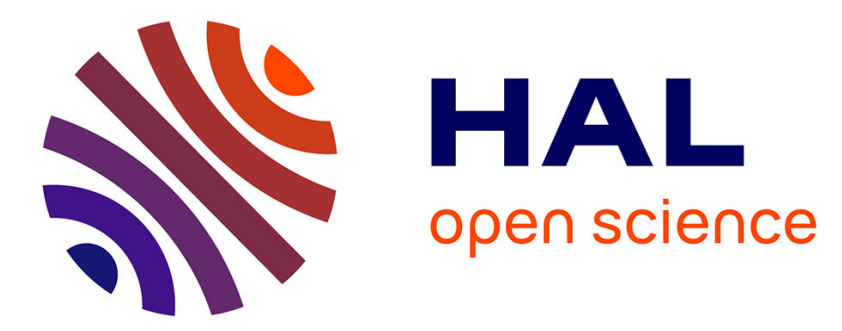

\title{
Unusually weak E1 transitions in 45Ti
}

\author{
A. Chevallier, Jacques Chevallier, B. Haas, N. Schulz, M. Toulemonde
}

\section{To cite this version:}

A. Chevallier, Jacques Chevallier, B. Haas, N. Schulz, M. Toulemonde. Unusually weak E1 transitions in 45Ti. Journal de Physique, 1980, 41 (3), pp.239-241. 10.1051/jphys:01980004103023900 . jpa00209238

\section{HAL Id: jpa-00209238 https://hal.science/jpa-00209238}

Submitted on 1 Jan 1980

HAL is a multi-disciplinary open access archive for the deposit and dissemination of scientific research documents, whether they are published or not. The documents may come from teaching and research institutions in France or abroad, or from public or private research centers.
L'archive ouverte pluridisciplinaire HAL, est destinée au dépôt et à la diffusion de documents scientifiques de niveau recherche, publiés ou non, émanant des établissements d'enseignement et de recherche français ou étrangers, des laboratoires publics ou privés. 


\title{
Unusually weak E1 transitions in ${ }^{45 T i}$
}

\author{
A. Chevallier, J. Chevallier, B. Haas, N. Schulz and M. Toulemonde \\ Centre de Recherches Nucléaires et Université Louis-Pasteur, 67037 Strasbourg, France
}

(Reçu le 12 octobre 1979, accepté le 19 novembre 1979)

\begin{abstract}
Résumé. - Les décroissances des deux premiers états de parité positive du noyau ${ }^{45} \mathrm{Ti}$ ont été réexaminées à l'aide de spectres $\gamma$ obtenus en direct, en coïncidence $\gamma-\gamma$ et en coïncidence $n-\gamma$. Les probabilités de transition E1 observées (de l'ordre de $10^{-7}$ unités Weisskopf) sont jusqu'à 30 fois inférieures à la transition E1 la plus ralentie connue dans les autres noyaux de la région de masse $40<A<50$.

Abstract. - The $\gamma$ decay of the first two positive parity states in ${ }^{45}$ Ti was reexamined using single $\gamma$-ray, $\gamma-\gamma$ coincidence and $n-\gamma$ coincidence techniques. E1 transition strengths down to $10^{-7}$ Weisskopf units were deduced from the experimental data, which is 30 times lower than the weakest E1 transition known in the other nuclei of the mass region $40<A<50$.
\end{abstract}

1. Introduction. - Electromagnetic transition strengths between bound states for light nuclei have been reviewed by Endt and Van der Leun [1]. The values of the two weakest E1 transitions reported, namely the $2^{-} \rightarrow 2^{+}$transitions in ${ }^{22} \mathrm{Ne}$ and ${ }^{44} \mathrm{Sc}$, have since been reevaluated $[2,3]$ and found to be equal to $9.8 \times 10^{-6}$ and $4.1 \times 10^{-6}$ Weisskopf units (W.u.), respectively. According to Ref. [1] and a survey of all E1 transitions for $40<A<50$ nuclei [4], the weakest transition has a strength of $(2.9 \pm 0.5) \times 10^{-6}$ W.u. (the $3^{-} \rightarrow 2^{+}$transition in $\left.{ }^{44} \mathrm{Sc}\right)$. Theoretically E1 transitions with even larger hindrance factors can exist and the reason they remain largely unreported may be the experimental difficulties in observing them. As a matter of fact, an E1 transition with a strength of

$$
(0.85 \pm 0.06) \times 10^{-7} \text { W.u. }
$$

has recently been observed in the ${ }^{21} \mathrm{Ne}$ nucleus [5]. In order to find out if other E1 transitions with unusually weak strengths exist, the $\gamma$-decay of the first two positive parity states in ${ }^{45} \mathrm{Ti}$ was reexamined (see Fig. 1).

2. Experimental procedure and results. $-2.1 \mathrm{THE}$ $329 \mathrm{keV}$ LEVEL. - The $329 \mathrm{keV}$ level was populated $0.7 \mathrm{MeV}$ above threshold through the ${ }^{45} \mathrm{Sc}(p, n \gamma)$ reaction at a proton energy of $3.6 \mathrm{MeV}$. The bombarding energy was chosen in order to strongly excite the state and at the same time to avoid $\gamma$-ray lines in the spectra arising from higher excited states.
The target consisted of a deposit of $600 \mu \mathrm{g} / \mathrm{cm}^{2}$ of scandium on a $0.1 \mathrm{~mm}$ thick gold backing. Gamma rays were detected in a $1.7 \mathrm{~cm}^{3} \mathrm{Ge}(\mathrm{Li})$ detector with a resolution of $1.0 \mathrm{keV}$ at $300 \mathrm{keV}$ and positioned at an angle of $55^{\circ}$ to the beam axis.

Singles $\gamma$-ray spectra revealed a weak line, $3.3 \pm 0.3 \mathrm{keV}$ below the well known $329 \rightarrow 37 \mathrm{keV}$ $\gamma$-transition (see Fig. 2). This line could correspond to the $329 \rightarrow 40 \mathrm{keV} \gamma$-transition, since the energy difference between the two first excited states in ${ }^{45} \mathrm{Ti}$ is $3.5 \pm 0.4 \mathrm{keV}$ [6]. A branching ratio of $0.55 \pm 0.25 \%$ is deduced for this transition from the recorded spectra.

The origin of this line was unambiguously confirmed by $\gamma-\gamma$ coincidences in the ${ }^{42} \mathrm{Ca}(\alpha, n \gamma)$ reaction at $8 \mathrm{MeV}$ bombarding energy. The $40 \mathrm{keV} \gamma$-ray was viewed by the $1.7 \mathrm{~cm}^{3} \mathrm{Ge}(\mathrm{Li})$ detector, whereas more energetic $\gamma$-transitions were detected by a $9 \mathrm{~cm}^{3} \mathrm{Ge}(\mathrm{Li})$ detector having a resolution of $1.4 \mathrm{keV}$ at $300 \mathrm{keV}$. A time window of $30 \mathrm{~ns}$ was used in this experiment in order to accept most of the delayed $40 \mathrm{keV} \gamma$-rays since the mean life of the $40 \mathrm{keV}$ level is $16.6 \mathrm{~ns}$.

2.2 THE $744 \mathrm{keV}$ LEVEL. - The $\gamma$ decay of the $744 \mathrm{keV}$ level was studied using $n-\gamma$ coincidence techniques. Neutrons arising from the ${ }^{45} \operatorname{Sc}(p, n \gamma)$ reaction at $E_{p}=4.0 \mathrm{MeV}$ were detected at $0^{\circ}$ to the beam axis in a $5 \mathrm{~cm}$ thick, $12.5 \mathrm{~cm}$ diameter NE213 detector. The $\gamma$-ray flux in the neutron detector was reduced by a $4 \mathrm{~cm}$ thick lead shield. Neutrons were 


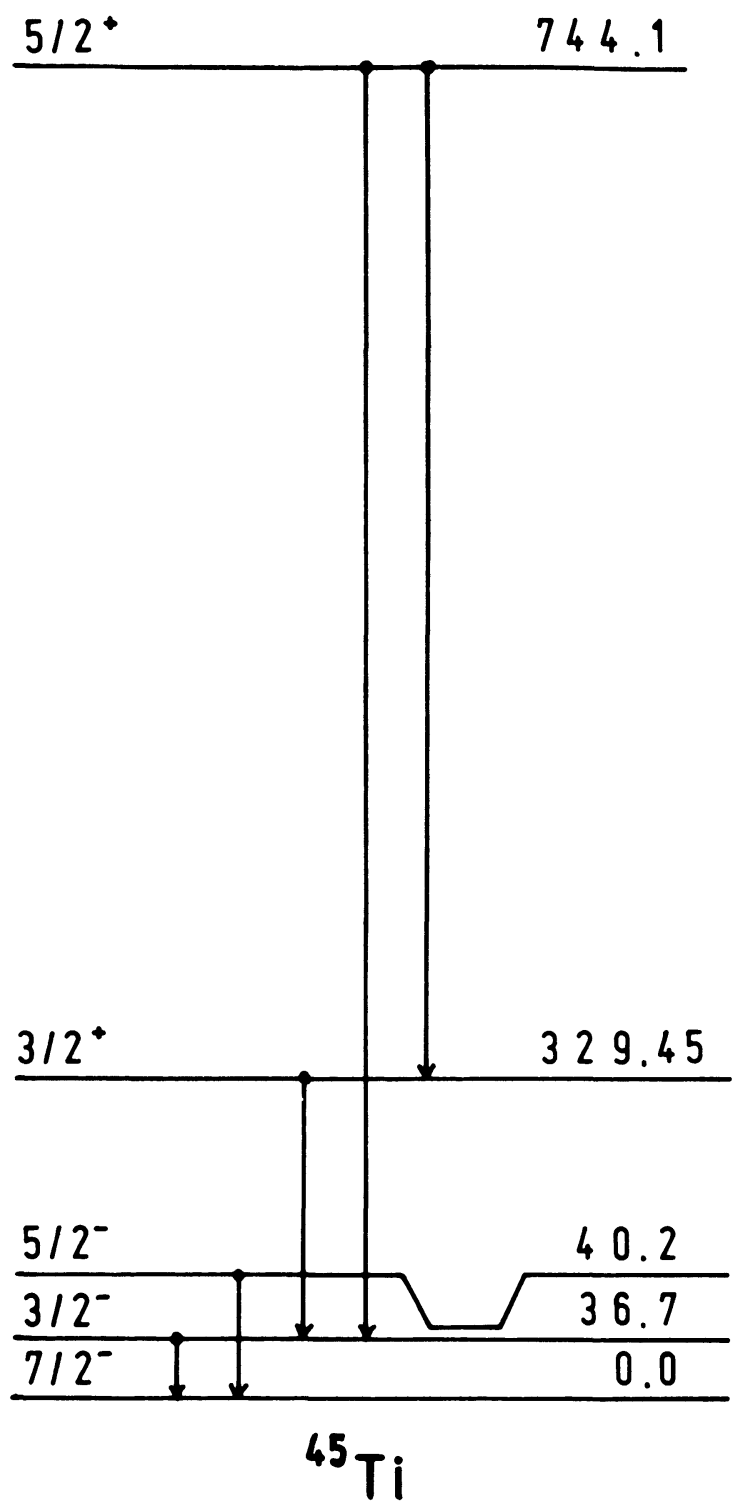

Fig. 1. - Decay scheme for ${ }^{45} \mathrm{Ti}$ levels below $1 \mathrm{MeV}$ excitation as reported in Ref. [6]. The $J=5 / 2$ assignment to the $40 \mathrm{keV}$ level was made by Styczen et al. [7].

discriminated from the remaining $\gamma$-rays by time of flight, with a flight path of $52 \mathrm{~cm}$. Gamma rays were detected in a $40 \mathrm{~cm}^{3} \mathrm{Ge}(\mathrm{Li})$ detector positioned at $55^{\circ}$ to the beam axis. A lead absorber set in front of the $\mathrm{Ge}(\mathrm{Li})$ counter attenuated the intensity of the low energy $\gamma$-rays and effectively eliminated summing effects. Two parameter spectra were recorded with the time spectrum in a 256 channel resolution and the $\mathrm{Ge}(\mathrm{Li})$ pulses in a 1024 channel resolution. Selected parts of the coincident $\gamma$-ray spectrum obtained after random substraction are displayed in figure 3 . Corrected for the relative detector efficiency, the intensities of the three lines feeding the lower negative parity states, yield the branching ratios $R$ for the corresponding three E1 transitions (Table I).

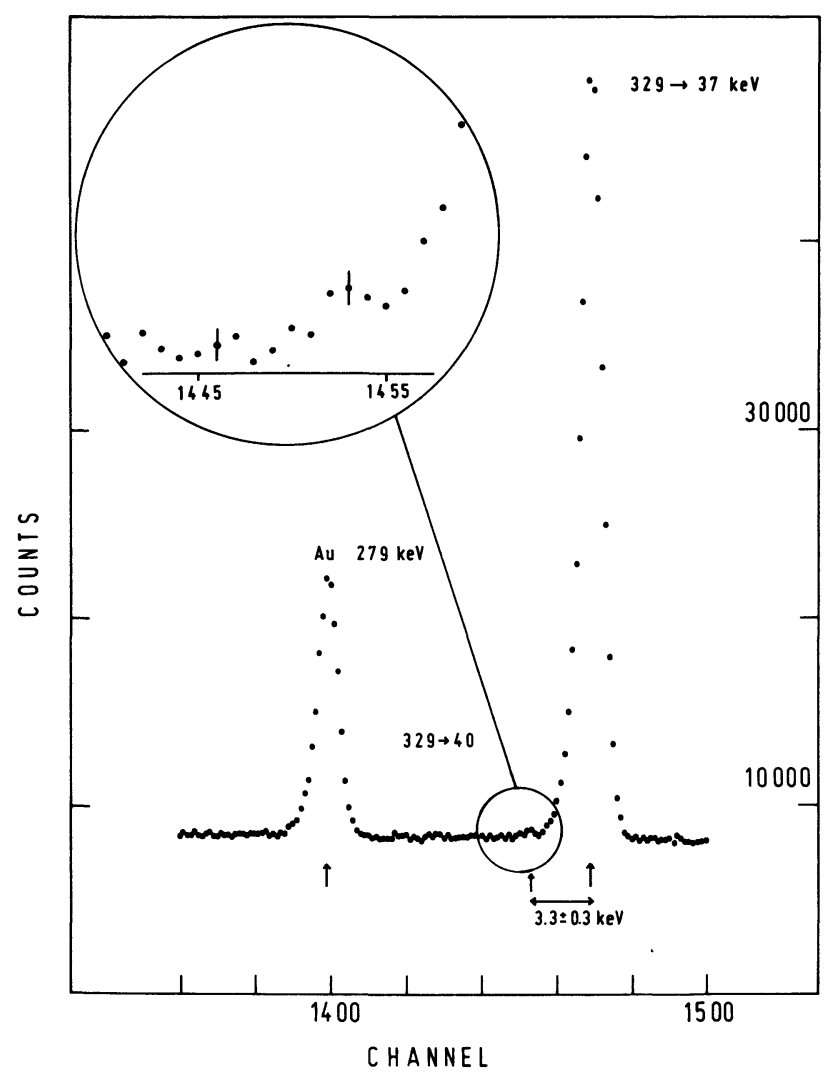

Fig. 2. - Portion of a singles $\gamma$-ray spectrum taken in the ${ }^{45} \operatorname{Sc}(p, n \gamma)$ reaction at $E_{p}=3.6 \mathrm{MeV}$.

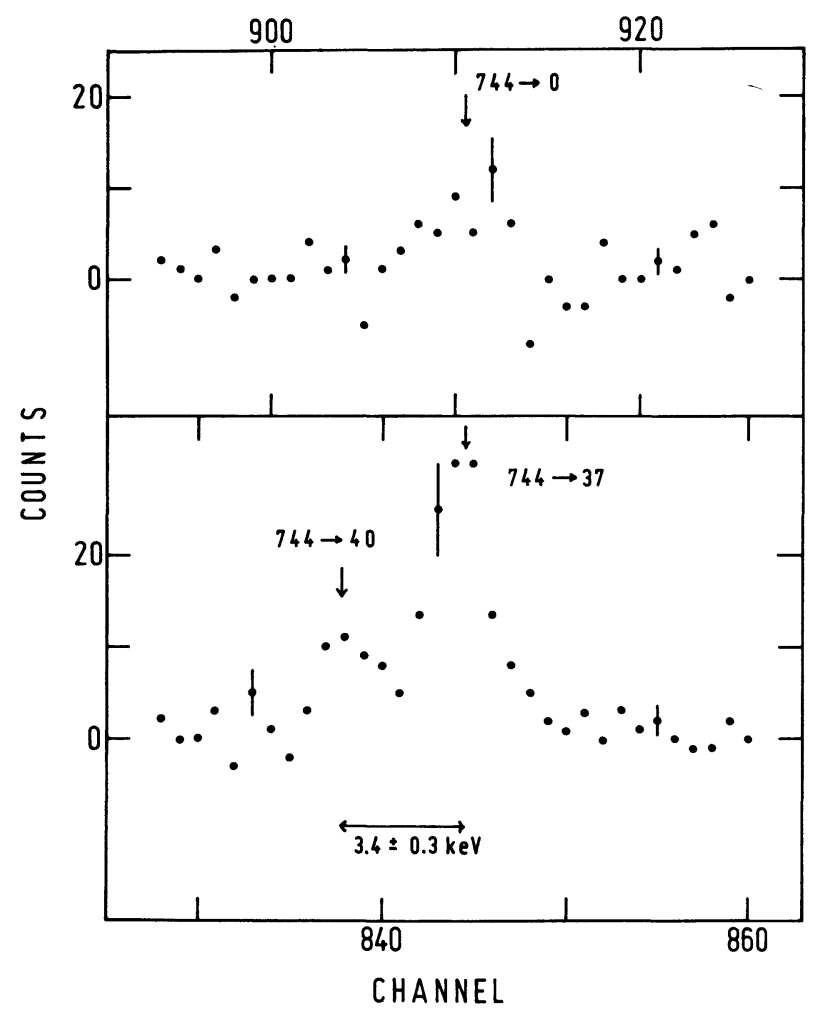

Fig. 3. - Selected parts of the spectrum of $\gamma$-rays in coincidence with neutrons feeding the $744 \mathrm{keV}$ level, after random substraction. 
Table I. - E1 transitions issuing from the 329 and $744 \mathrm{keV}$ levels in ${ }^{45} \mathrm{Ti}$.

$$
\begin{array}{rlrl}
E_{\mathrm{i}} & \rightarrow E_{\mathrm{f}} \\
(\mathrm{keV}) & J_{\mathrm{i}}^{\pi} & \rightarrow J_{\mathrm{f}}^{\pi} \\
- & & - \\
329 & \rightarrow 37 & 3 / 2^{+} & \rightarrow 3 / 2^{-} \\
& \rightarrow 40 & & \rightarrow 5 / 2^{-} \\
744 & \rightarrow 0 & 5 / 2^{+} & \rightarrow 7 / 2^{-} \\
& \rightarrow 37 & \rightarrow 3 / 2^{-} \\
& \rightarrow 40 & & \rightarrow 5 / 2^{-}
\end{array}
$$

$$
\begin{gathered}
\frac{\tau\left({ }^{a}\right)}{-} \\
1.72 \pm 0.10 \mathrm{~ns} \\
14.5 \pm 2.5 \mathrm{ps}
\end{gathered}
$$

$R$
$(\%)$
-
$99.45 \pm 0.25$
$0.55 \pm 0.25$
$0.2 \pm 0.1$
$6.8 \pm 0.7$
$2.4 \pm 0.4$

$\left({ }^{a}\right)$ Ref. [8].

3. Conclusion. - Three weak E1 transitions have been observed in the present work. Whether the reason similar weak transitions have not been reported is due to experimental difficulties or to a special aspect of nuclear structure in ${ }^{45} \mathrm{Ti}$ is up to now an unanswered question. Parity mixing in the parent level has been proposed to explain the strong inhibition of the $1 / 2^{-} \rightarrow 3 / 2^{+}$E1 transition in ${ }^{21} \mathrm{Ne}$ [9]. Such an explanation would not hold for the present transitions.

\section{References}

[1] Endt, P. M. and van Der Leun, C., Nucl. Phys. A 235 (1974) 27.

[2] Merdinger, J. C., Bozek, E., Gehringer, C. and Stachura, Z., Phys. Lett. 59B (1975) 38.

[3] Chevallier, A., Chevallier, J., Gross, J. L., HaAs, B., Schulz, N., Styczen, J. and Toulemonde, M., Z. Phys. A 275 (1975) 51

[4] Chevallier, A., Chevallier, J., HaAs, B., Schulz, N. and ToulEmonde, M., Internal Report CRN/PN 78-18, Strasbourg.
[5] Freeman, R. M., HaAs, F., Heusch, B. and Gallmann, A., Nucl. Phys. A 261 (1976) 471.

[6] BEENE, J. R., Nuclear Data Sheets 22 (1977) 1.

[7] Styczen, J., Chevallier, A., Chevallier, J., HaAs, B., Schulz, N. and Toulemonde, M., Phys. Rev. C 15 (1977) 1704.

[8] Blasi, P., Morando, M., Maurenzig, P. R. and Tacceti, N., Nuovo Cimento Lett. 2A (1971) 63.

[9] Millener, D. J., Bull. Amer. Phys. Soc. 23 (1978) 499. 